\title{
Evidence for the presence of a kininogen-like species in a case of total deficiency of low and high molecular weight kininogens
}

D. Veloso
Department of Psychiatry and Behavioral Sciences, Mental Sciences Institute, University of Texas at Houston, Houston, TX, USA

\section{Correspondence \\ D. Veloso \\ Department of Psychiatry and \\ Behavioral Sciences \\ Mental Sciences Institute \\ UT-Houston \\ 1300 Moursund \\ Houston, TX 77030 \\ USA \\ Fax: (713) 500-2530 \\ E-mail: \\ dveloso@msi66.msi.uth.tmc.edu \\ Part of this work was published as an abstract (FASEB Journal, 1996; 10: \\ 1526) and was presented as an oral communication at the International Symposium KIN IN '95, Denver.}

Received O ctober 22, 1997 Accepted April 24, 1998

\begin{abstract}
Low and high molecular weight kininogens (LK and HK), containing 409 and 626 amino acids with masses of $\sim 65$ and $120 \mathrm{kDa}$ after glycosylation, respectively, are coded by a single gene mapped to the human chromosome 3 by alternative splicing of the transcribed mRNA. The $\mathrm{NH}_{2}$-termini $\mathrm{Glu}^{1}-\mathrm{Thr}^{383}$ region, identical in LK and HK, contains bradykinin (BK) moieties $\mathrm{Arg}^{363}-\mathrm{Arg}^{371}$. LK, HK and their kinin products Lys-BK and BK are involved in several biologic processes. They are evolutionarily conserved and only 7 patients, all apparently normal, have been reported to lack them. In one of these patients (Williams' trait), a codon mutation ( $\operatorname{Arg}^{178} \rightarrow$ stop) has been blamed for the absence of LK and HK. However, using Western blots with 2 monoclonal anti-HK antibodies, one that recognizes the region common to LK and HK and the other that recognizes only HK, I detected $\sim 110-\mathrm{kDa}$ bands in the plasma of this LK/HK-deficient patient $v s$ $\sim 120-\mathrm{kDa}$ bands in normal human and ape plasmas. With polyclonal anti-Lys-BK antibody, which strongly detects $\mathrm{BK}$ cleaved at its $\mathrm{COOH}-$ terminus in purified HK, I detected $\sim 110$-kDa bands in the normal and the deficient plasmas. Western blots with a monoclonal antiprekallikrein (PK) antibody showed that surface activation of PK and distribution of PK activation products, both dependent on HK, were similar in these plasmas. These findings suggest that a mutant gene yielded a kininogen-like species possibly involving aberrant mRNA splicing - structurally different from normal $\mathrm{HK}$, but apparently with the capacity to carry out seemingly vital HK functions.
\end{abstract}

\section{Introduction}

Kininogens and their cleavage products kinins are multifunctional molecules well perserved in evolution $(1,2)$. In humans, low (LK) and high molecular kininogens (HK) ( $\sim 65 \mathrm{kDa}$ and $\sim 120 \mathrm{kDa}$, respectively) are single chain glycoproteins, which contain kinin moieties. Specific hydrolyses of LK

\author{
Key words \\ - Kininogen deficiency \\ - Kinins \\ - Antibodies \\ - Plasma \\ - Kininogen-like species \\ - Human and nonhuman \\ primates
}

and HK, catalyzed by tissue and plasma kallikreins, release Lys-bradykinin (Lys-BK) and BK, respectively, and divide each kininogen into 2 fragments, heavy and light chains, bridged by a disulfide bond. Both LK and HK stem by alternative splicing of the mRNA transcribed from a single gene mapped to chromosome 3q26-qter in humans that contains 11 exons $(3,4)$. The identical sequences 
of LK and HK heavy chains - 362 amino acids (aa) - are encoded by exons 1-10 (5). Exon 10 also encodes Lys-BK and BK (10 and 9 aa, respectively), part of LK light chain (12 aa) and the entire HK light chain (255 aa), and exon 11 encodes the 26 aa of the $\mathrm{COOH}$-terminal sequence of LK light chain. The homology among the genes that encode human, cow and rat LK and HK, rat T-I and T-II kininogens and human stephins and cystatins shows that they originate from the same ancestor $(5,6)$. It also shows that the function of these proteins as cysteine protease inhibitors, with activities located in LK/HK heavy chains, has been conserved through evolution (6-8). In addition, activation of the contact system of coagulation, as assayed in vitro, requires binding of $\mathrm{HK}$ light chain to prekallikrein (PK) and factor XI. The fact that kininogens and kinins have been conserved through evolution, participate in multiple biologic processes including inflammation, regulation of blood pressure and vascular permeability, cardioprotection and pain modulation (9-17), and that kinin receptors are ubiquitous in mammalian tissues, including brain, suggests that HK/LK and kinins are essential to normal biologic functions. Nevertheless, 7 persons have been reported to be totally deficient in HK/LK. In each case they appeared to be physiologically normal. Genetic analysis done in only one of these patients (Williams' trait (18)) by Cheung et al. (19) attributes this deficiency to a codon mutation ( $\mathrm{Arg}^{178} \rightarrow$ stop) in exon 5. These authors suggest that their failure to detect the expected $21.5-\mathrm{kDa}$ truncated protein could be explained by stability or transport anomalies of the defective protein.

However, the unexpected detection of a $\sim 110-\mathrm{kDa}$ band on Western blots of Williams' trait plasma with the monoclonal antiHK light chain antibody mAb 371-28 (20), in our laboratory, indicated the presence of a kininogen-like species in this plasma. This finding was confirmed, as described in the present report, by comparing Western blots of Williams' plasma with those of normal human and ape plasmas, which show intact $\sim 120-\mathrm{kDa}$ HK with mAb 371-28 and the anti-LK/HK heavy chain mAb 11-2 (21), and cleaved $\sim 110-\mathrm{kDa}$ HK with anti-LysBK (22) and anti-BK (23) antibodies. In addition, HK function was tested by comparing PK activation on a surface and distribution of its activation products, which depend on HK $(24,25)$, in the deficient and normal plasmas (preliminary report, Ref. 26).

\section{Material and Methods}

\section{Sources of chemicals, plasmas and antibodies}

The source and grade of chemicals have been reported before (27). Solutions of purified human plasma HK (Enzyme Research Laboratories, South Bend, IN) were adjusted to a neutral $\mathrm{pH}$ with Tris before the assay. SDS-PAGE analysis of the reduced and the nonreduced neutralized HK showed only a $\sim 120-\mathrm{kDa}$ band. The following plasmas were obtained from George King Biomedicals (Overland Park, KS): pooled, normal human plasma; PK-deficient plasma with PK undetectable by clotting, amidolytic and Western blot assays, and kininogen-deficient, Williams' trait plasma lot GK1602-316E1. Chimpanzee (Pan troglodytes) and orangutan (Pongo pygmaeus) plasmas were kindly supplied by the Yerkes Regional Primate Research Center (Atlanta, GA). Blood from a female (D) and a male (T) was drawn into tubes containing $3.8 \%$ sodium citrate and $2.5 \%$ dextrose (9 blood:1 citrate/dextrose mixture, v:v). Blood was centrifuged for 5 min at $2,000 \mathrm{~g}$, at $23^{\circ} \mathrm{C}$. One sample of plasma $\mathrm{T}$ was frozen and thawed several times, which resulted in marked activation. Only plasticware or siliconized glassware was used for blood or plasma samples.

Monoclonal anti-human plasma heavychain PK antibody (mAb 13G11) (28) - patents: U.S. \#5,444,156, European \# 0210029, 
and Canadian \#1312564, inventors D.C. Veloso and R.W. Colman - was purified from ascites produced at Temple University. and was provided by that University. The following antibodies were generous gifts: mAbs 371-28 and 11-2 from Dr. Sesha Reddigari and Dr. Allen P. Kaplan, and rabbit polyclonal anti-BK and anti-Lys-BK antibodies from Dr. David Proud and Dr. A. Guillermo Scicli, respectively. "Blotting detection kit for mouse antibodies" ("Amersham kit") was supplied by Amersham Corp. (Arlington Heights, IL), and alkaline phosphatase affinity purified goat anti-rabbit IgG by Cappel, Organon Teknika Corp., West Chester, PA. Plasmas and antibodies were stored at $<-70^{\circ} \mathrm{C}$.

\section{Amidolytic and clotting activities}

Amidolytic activity was determined as reported by Veloso et al. (27). Briefly, activation was effected by mixing plasmas with an equal volume of a kaolin suspension (1 $\mathrm{mg} / \mathrm{ml} 0.15 \mathrm{M} \mathrm{NaCl}$ ) for $5 \mathrm{~s}$ in a Vortex, followed by a 55 -s incubation at $23^{\circ} \mathrm{C}$. Initial velocities of D-Pro-Phe-Arg-p-nitroanilide hydrolysis $(0.8 \mathrm{mM}$ at zero times) in the activated plasmas (5-15 $\mu \mathrm{l})$ were measured at $37^{\circ} \mathrm{C}$ and $405 \mathrm{~nm}$ with a Beckman DU-7 spectrophotometer. Clotting activity was determined by the method of Proctor and Rapaport (29) using the GK1602-316E1 plasma as source of proteins.

\section{mAb 13G11 iodination}

The method of Fraker and Speck Jr (30) was used. To conical tubes $(1.5 \mathrm{ml})$, partially coated with $20 \mu \mathrm{g}$ IODO-GEN $(1,3,6$, 6tetrachloro-3 $\alpha, 6 \alpha$-diphenylglycoluril), mAb 13G11 (200 $\mu \mathrm{g} / 200 \mu \mathrm{l}$ of $10 \mathrm{mM}$ Tris-HCl/ $100 \mathrm{mM} \mathrm{NaCl}, \mathrm{pH}$ 7.5) previously mixed with $\sim 3.7 \times 10^{7} \mathrm{~Bq}$ of iodine-125 was added and incubated at $23^{\circ} \mathrm{C}$ for $15-30 \mathrm{~min}$. The reaction was stopped with $10 \mu 1$ of $0.1 \%$ sodium metabisulfite followed by separa- tion of ${ }^{125} \mathrm{I}-\mathrm{mAb} 13 \mathrm{G} 11$ from free iodine125 by gel filtration on Sephadex G-25 with the Tris buffer. The specific activity was $2 \mathrm{x}$ $10^{3} \mathrm{~Bq} / \mu \mathrm{g} \mathrm{mAb} 13 \mathrm{G} 11$. The ${ }^{125} \mathrm{I}-\mathrm{mAb} 13 \mathrm{G} 11$ was then diluted about 3 -fold with unlabeled $\mathrm{mAb}$ and stored at $4^{\circ} \mathrm{C}$.

\section{Western blots}

Plasmas $(8 \mu \mathrm{l})$ with or without kaolin activation were subjected to SDS/7.5, 8.0 or $10 \%$-PAGE according to Laemmli (31) using a standard size Hoefer apparatus as described by Veloso et al. (27). Briefly, plasma was activated by mixing with an equal volume of a kaolin suspension $(5 \mathrm{mg} / \mathrm{ml} 0.15 \mathrm{M}$ $\mathrm{NaCl}$ ) in a Vortex for $5 \mathrm{~s}$ followed by incubation at $4^{\circ} \mathrm{C}$ for $2 \mathrm{~h}, 23^{\circ} \mathrm{C}$ for $20 \mathrm{~min}$ or $37^{\circ} \mathrm{C}$ for $15 \mathrm{~min}$, and centrifugation $(1,000 \mathrm{~g}, 3$ min). For immunoblotting of the resulting electrophoretogram, the method of Towbin et al. (32), as modified by Burnette (33), was used, except that electrotransfer to nitrocellulose membranes was done at $10^{\circ} \mathrm{C}$ for 15 $17 \mathrm{~h}$ with a Transphor model TE50 (Hoefer Scientific Instruments, San Francisco, CA). Free sites were blocked with $5 \%$ casein adjusted to $\mathrm{pH} 7.4$ with Tris (2-h incubation, $23^{\circ} \mathrm{C}$ ). The same casein solution containing $0.05 \%(\mathrm{w} / \mathrm{v})$ NONIDET P-40 was used for washing the membranes (4-5 times followed by rinsing with $\mathrm{H}_{2} \mathrm{O}$ ) after their incubation $\left(2 \mathrm{~h}, 23^{\circ} \mathrm{C}\right)$ with the iodinated or diluted antibodies as follows: ${ }^{125} \mathrm{I}-\mathrm{mAb} 13 \mathrm{G} 11(\sim 1$ $\mu \mathrm{g}, 6 \times 10^{2} \mathrm{~Bq} / \mathrm{ml}$ ) for PK/kallikrein detection as reported (34); mAb 371-28 (2.5 $\mu \mathrm{g} /$ $\mathrm{ml})$ or $\mathrm{mAb} 11-2(3 \mu \mathrm{g} / \mathrm{ml})$ for kininogen binding followed by detection with sheep anti-mouse biotinylated antibody (the secondary antibody) and a streptavidin-biotinylated phosphatase complex as the signal generating system, as described by the "Amersham kit" manufacturers, and Proud's antibody (diluted 20,000-fold) or Scicli's freeze-dried antibody $\left(1 \mathrm{ml}\right.$ of $\mathrm{H}_{2} \mathrm{O}$ added before a 2,500-fold dilution) for binding of the $\mathrm{COOH}$-termini of BK or Lys-BK fol- 
lowed by binding to goat anti-rabbit antibody conjugated to alkaline phosphatase (diluted 1,500-fold). Antibodies were diluted with the casein solution. Nitro-blue tetrazolium and 5-bromo-4-chloro-3-indoyl phosphate dissolved in diethanolamine containing $5 \mathrm{mM} \mathrm{MgCl} \mathrm{Mere}_{2}$ we substrates in the alkaline phosphatase reactions. For comparison of proteins detected by different antibodies, after free site blocking, the membrane was split and then processed separately.

\section{Results}

\section{Recognition of kininogens or kininogen-like proteins in Williams' trait plasma}

A $\sim 110-\mathrm{kDa}$ band was recognized by mAb 371-28 on Western blots of the HK/ LK-deficient plasma GK1602-316E1 (Williams' trait plasma). Like normal human and orangutan plasmas, Williams' plasma showed only the $\sim 85$ - and 88 -kDa PK variants seen in normal plasmas (Figure 1A). PK concentrations determined by densitometry of the autoradiographs of the Western blots were $48 \%$ those in normal human plasma, a value comparable to that of $45 \%$ first reported for Williams' plasma (18). Figure 1B shows that, unlike PK-deficient plasma and normal human and chimpanzee plasmas, a $\sim 110$ $\mathrm{kDa}$ band(s), and not the 120-kDa HK band observed in normal plasmas, was detected in the deficient plasma with mAb 371-28. An additional $\sim 110$-kDa band, also observed in the PK-deficient plasma, is probably an HK degradation product.

\section{Recognition of the HK heavy and light chains by monoclonal antibodies in normal and Williams' plasmas}

Similar to mAb 371-28 (Figure 2A), mAb 11-2, which specifically recognizes the heavy chain shared by HK and LK, also recognized the $\sim 110-\mathrm{kDa}$ band in the Williams' plasma and the $120-\mathrm{kDa}$ band in normal human and chimpanzee plasmas (Figure 2B). The 90$103-\mathrm{kDa}$ bands probably correspond to cleaved HK. mAb 11-2 barely detected LK on Western blots of the deficient or normal plasmas.

\section{Detection of a kinin antigen(s) in Williams' plasma}

mAb 371-28 recognized $~ 120-k D a$ bands in purified $\mathrm{HK}$ at a position similar to that in normal human and chimpanzee plasmas and also the $\sim 110-\mathrm{kDa}$ band in the Williams' plasma (Figure 3A). Reactivity of these proteins was also compared with those processed under similar conditions using Scicli's polyclonal anti-Lys-BK antibody (Figure 3B), which specifically recognizes BK cleaved at its $\mathrm{COOH}$-terminus in $\mathrm{HK}$ or $\mathrm{HK}$ fragments (35). Scicli's antibody recognized bands at similar positions in the deficient and normal human plasmas (Figure 3B) but not in purified $\mathrm{HK}$, apparently because the purified $\mathrm{HK}$ was intact. Bands of $\sim 110 \mathrm{kDa}$ were also detected on blots of the Williams' and the $\mathrm{D}$ and T plasmas with Proud's polyclonal antiBK antibody (Figure 4B), while immunoblots run simultaneously with mAb 371-28 showed the expected 110 - and the $120-\mathrm{kDa}$ bands in their plasmas (Figure 4A). Intense bands (90 to $103 \mathrm{kDa}$ ) were detected with both $\mathrm{mAb}$ 371-28 and Proud's antibody on blots of the $\mathrm{T}$ plasma activated by several freeze-thaw cycles (lanes 3 of Figure 4A and B). As expected, an increase of cleaved HK in this activated plasma was accompanied by a decrease of intact, 120-kDa HK (Figure 4A, lane 3). Curved, fine bands ( $\sim 50 \mathrm{kDa})$, visible on some of the kininogen blots, have not yet been identified.

\section{Comparison of the distribution of PK and its activation products in Williams' and normal plasmas}

Similar to normal human and orangutan 
Figure 1 - Western blots of PK and HK (or HK-like species) in PK-deficient, Williams', normal human, orangutan and chimpanzee plasmas. Proteins in plasmas $(8 \mu \mathrm{l})$, resolved by SDS/10\% PAGE, were detected as follows:

A, PK in Williams' (lane 1), normal human (lane 2) and orangutan (lane 3 ) plasmas was probed with ${ }^{125}$ I-mAb 13G11;

B, HK or HK-like species in PK-deficient (lane 1), Williams' plasma (lane 2) and normal (lane 3) and chimpanzee (lane 4) plasmas were probed with mAb 371-28 (Amersham kit). Molecular masses of PK (85 and 88 $\mathrm{kDa})$, HK (120 kDa) or HK-like species (110 kDa) are indicated.

Figure 2 - Western blots of light and heavy chains of HK or HK-like species in Williams', normal human and chimpanzee plasmas. Western blots of Williams' (lane 1), normal human (lane 2) and chimpanzee (lane 3) plasmas were prepared as described in the legend to Figure 1 and probed by using:

A, anti-HK light chain mAb 371-28 (Amersham kit);

B, anti-HK heavy chain mAb 11-2 (Amersham kit). Molecular masses of HK (120 kDa), kininogen-like species (110 kDa) and HK heavy chains (A) or LK (B), each $\sim 63$ $\mathrm{kDa}$, are indicated.

Figure 3 - Western blots of HK and HK-like species in Williams' plasma, purified $\mathrm{HK}$, and normal human and chimpanzee plasmas. Proteins of plasmas $(8 \mu \mathrm{l})$ or purified HK $(2.4 \mu \mathrm{g})$ were resolved by SDS/10\% PAGE and probed as indicated. Williams' (lane 1), purified HK (lane 2), normal human (lane 3) and chimpanzee (lane 4) plasmas were probed with:

\section{A, anti-HK mAb 371-28;}

B, Scicli's polyclonal anti-Lys-BK antibody. Molecular masses of HK (120 kDa), HK-like species (110 kDa), cleaved kininogen (90-103 kDa) and an unidentified plasma component $(50 \mathrm{kDa})$ are indicated.
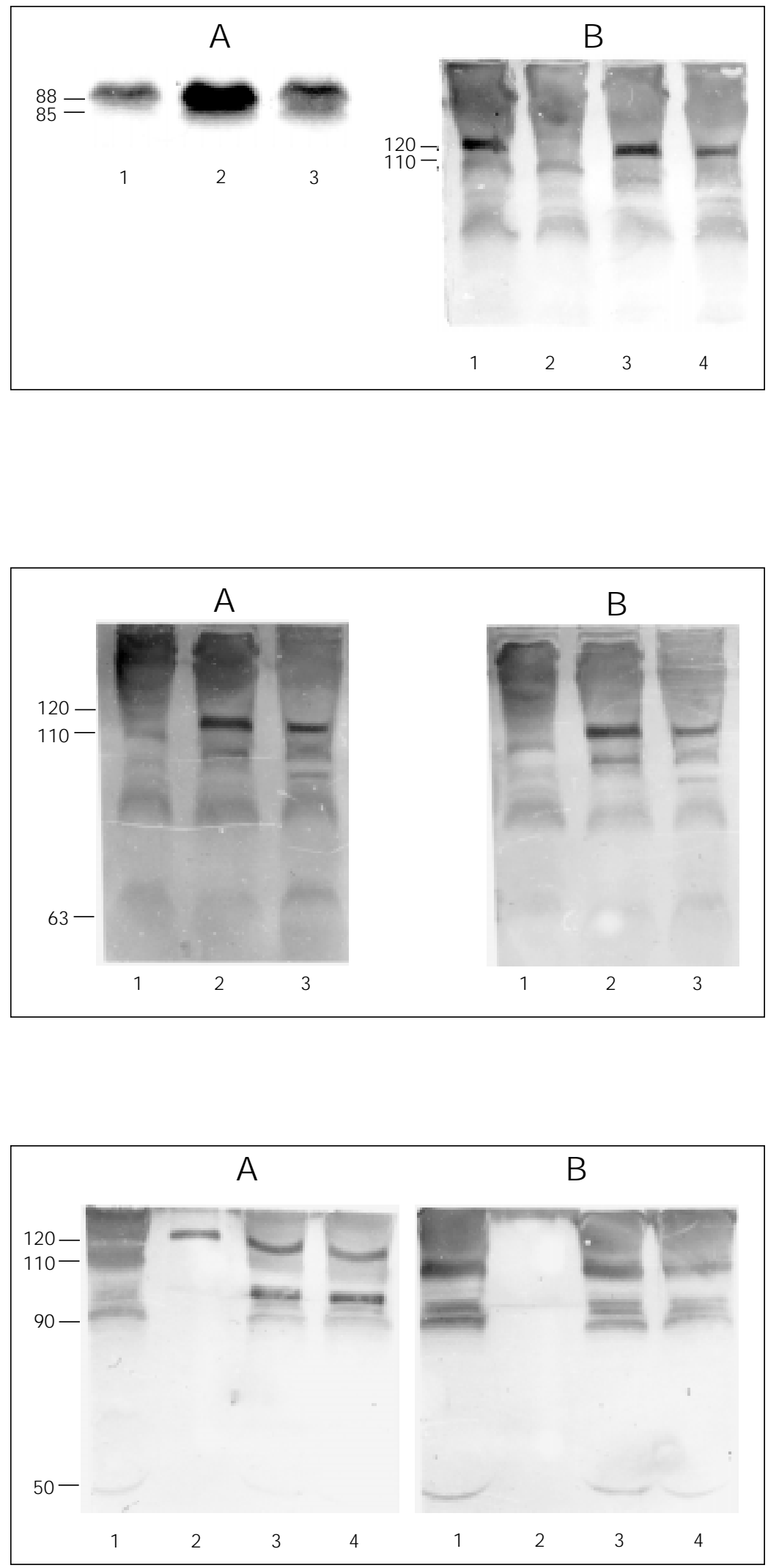
Figure 4 - Western blots of HK and HK-like species in Williams' and normal human plasmas. SDS/PAGE and Western blots of plasmas were done as indicated in the legend to Figure 1 with the following differences:

$\mathrm{A}, \mathrm{HK}$ or HK-like species in Williams' (lane 1), normal human female (D) (lane 2), and normal human male $(T)$ plasmas with and without further activation (lanes 3 and 4, respectively) were probed with mAb 371-28;

B, kinins in HK, HK-like species or their cleavage products in plasmas applied to gel lanes as indicated in (A) were probed with Proud's anti-BK antibody. Molecular masses of HK (120 $\mathrm{kDa}$ ) or HK-like species (110 $\mathrm{kDa})$, cleaved kininogen ( $\sim 90$ $\mathrm{kDa}$ ) and an unidentified component ( $\sim 50 \mathrm{kDa})$ are indicated.

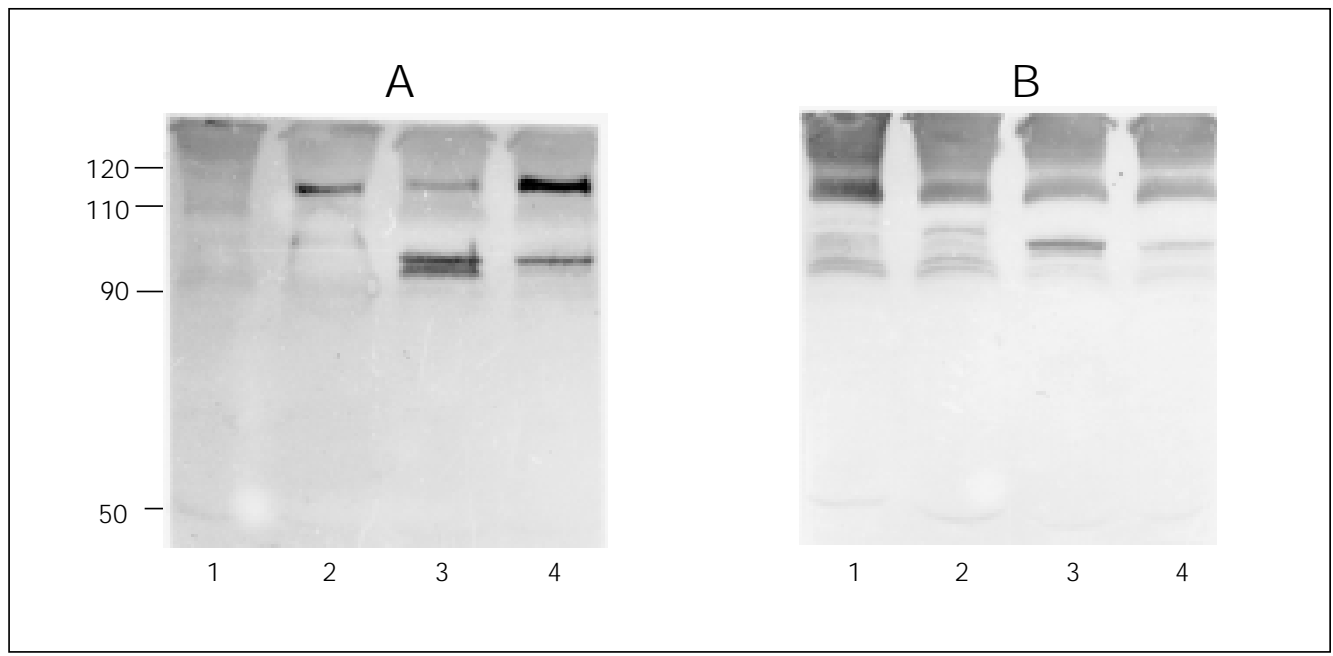

plasmas, Western blots of Williams' plasma activated with kaolin showed bands at the positions of the complexes of kallikrein- $\alpha_{2}-$ macroglobulin $\left(\alpha_{2} \mathrm{M}\right)$, kallikrein-C1 inhibitor, kallikrein-antithrombin, $\mathrm{PK}$ and $\sim 45-$ $\mathrm{kDa}$ fragments (Figure 5A-C). Similar to normal plasmas, deficient plasma kallikrein preferentially bound to $\mathrm{C} 1$ inhibitor at $37^{\circ} \mathrm{C}$ and to $\alpha_{2} \mathrm{M}$ at $4^{\circ} \mathrm{C}$, with an intermediate binding at $23^{\circ} \mathrm{C}$. The rate of $\mathrm{PK}$ activation or kallikrein activity at $4^{\circ} \mathrm{C}$ was apparently higher for normal human and orangutan plasmas than for Williams' plasma (Figure 5A). Although free kallikrein and PK positions overlap (28), undetectable amidolytic activities in the deficient plasma rules out any accumulation of free kallikrein at the PK position.

\section{Discussion}

This is the first report that provides evidence for the presence of kininogen-like species in a patient plasma, Williams' plasma, reported to lack LK and $\mathrm{HK}$ and not to be affected by their absence. To reconcile the apparently essential role of kinins and their kininogen precursors to normal biologic functions with their deficiency in apparently normal people, I hypothesized (36) that a compensatory biologic mechanism or the produc- tion of one or more mutant unstable proteins undetectable by the procedures then available, but potentially operative in vivo - might be present in the LK/HK deficient patients. In contrast, Cheung et al. (19) claimed that an $\operatorname{Arg}^{178} \rightarrow$ stop mutation in exon 5 of the Williams' kininogen gene was responsible for total LK/HK deficiency. Their efforts to detect the truncated $21.5-\mathrm{kDa}$ protein on Western blots with the anti-LK/HK heavy chain $\mathrm{mAb}$ 2B5 were unsuccessful, and a compensatory mechanism was not apparent. However, as shown in the present report (Figures 1-4), the anti-HK light chain mAb 371-28 detected a $\sim 110$-kDa band on Western blots of the deficient plasma $v$ s the expected $120-\mathrm{kDa}$ bands of normal human and ape plasmas; bands at these positions were also seen on Western blots with the anti-LK/HK heavy chains $\mathrm{mAb}$ 11-2 (Figure 2). mAb 11-2 did not detect LK on Western blots of Williams' or normal plasmas although it recognized purified LK and kininogen heavy chain, and normal human plasma with ELISA in microtiter plates $(20,21)$. Because this ELISA does not differentiate LK from $\mathrm{HK}$ in plasmas, one cannot rule out that the failure of mAb 11-2 to detect LK on Western blots was probably due to an effect of one or more plasma components on epitope availability. The lower intensity of the $110-\mathrm{kDa}$ bands recognized by mAb 371-28 and 11-2 on 


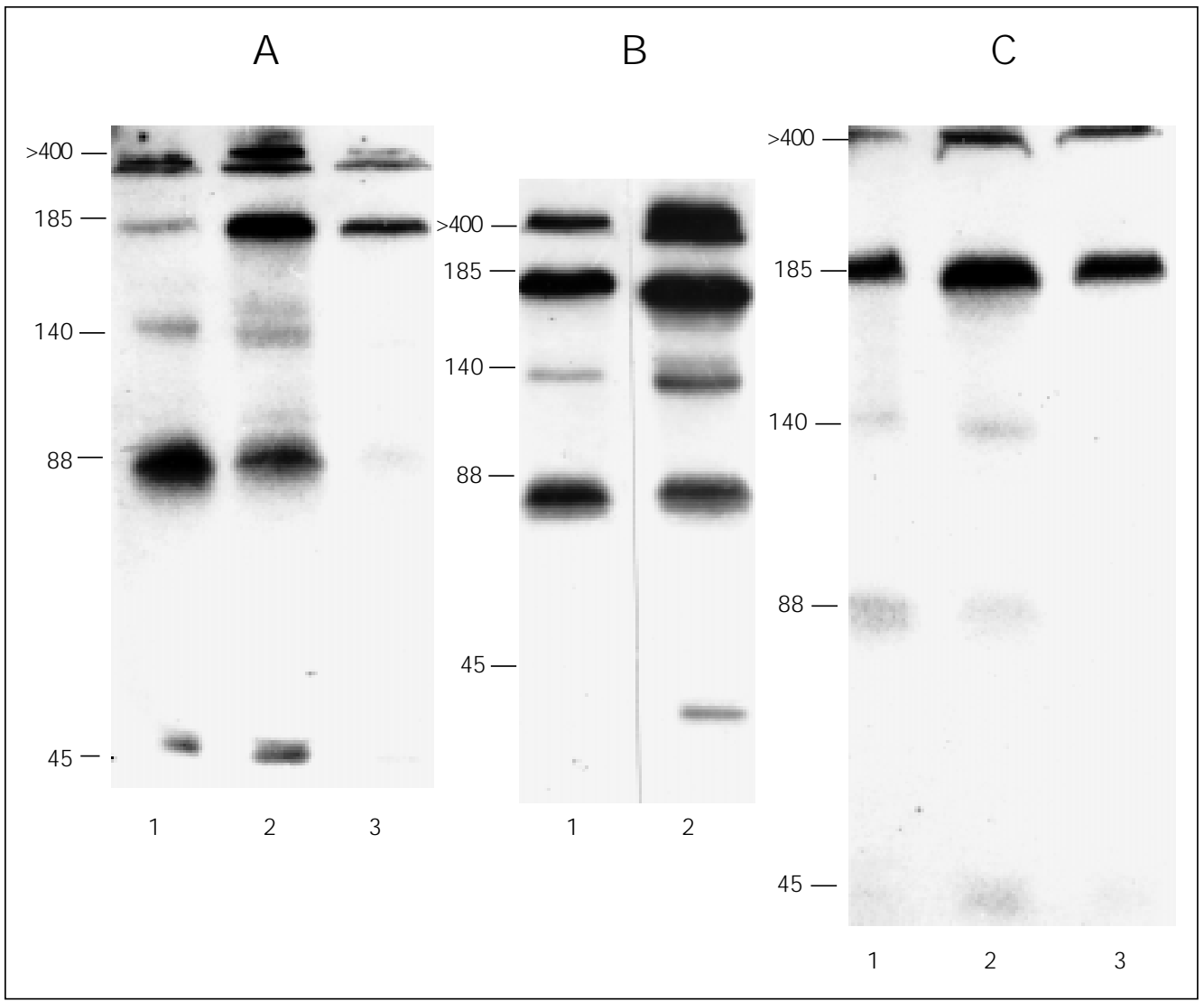

Williams' plasma - an apparent quantitative deficiency - might be due to an effect of the mutation on protein synthesis, transport or resistance to protease degradation. As a follow-up up step, the presence of kinins was investigated with Proud's anti-BK and Scicli's anti-Lys-BK antibodies. As expected from the study by Tayeh et al. (35), Scicli's antibody did not detect or barely detected the intact $\sim 120-\mathrm{kDa} \mathrm{HK}$ in purified $\mathrm{HK}$ and normal plasma. Also, as expected from the study by Tayeh et al. (35), this antibody strongly detected kinin in normal plasma with HK cleaved at its $\mathrm{COOH}$-terminus, which has a higher electrophoretic mobility than intact, purified HK, and kinin in Williams' plasma. The similar position of the bands detected with mAbs 371-28, 11-2 and anti-kinin antibodies in Williams' plasma in combination with the stronger detection by the anti-kinin antibodies than that by the mAbs suggests the presence of only kininogen cleaved at its $\mathrm{BK} \mathrm{COOH}$-terminus with no effect on electrophoretic mobility of the kininogen-like species - or epitope availability in the intact molecule due to structural changes. The failure of Scicli's (or Proud's) antibody to detect kinin in LK of normal or Williams' plasmas was probably due to LK intactness or structural changes affecting epitope detection. Further evidence for the presence of a kininogen-like species in the deficient plasma comes from the following: 1) the position of the bands ( 90 to $103 \mathrm{kDa}$ ) detected by mAb 371-28 and Scicli's and Proud's antibodies in both normal and deficient plasmas was comparable to that of the bands detected in purified $\mathrm{HK}$ cleaved by kallikrein by $\mathrm{mAb}$ 371-28 (20) and Scicli's antibody (35), and 2) the intensity of these bands was stronger in the plasma subjected to activation with several freeze-thaw cycles. Differences between band positions in normal and deficient plasmas could
Figure 5 - Distribution of PK and its derivatives in Williams', normal human and orangutan plasmas activated with kaolin at 4 , 23 and $37^{\circ} \mathrm{C}$. Autoradiographs shown were obtained from Western blots detected with 125I-mAb 13G11. Plasmas ( $8 \mu \mathrm{l})$ and their treatment were as follows:

A, Williams' (lane 1), normal human (lane 2) and orangutan (lane 3) plasmas were activated at $4^{\circ} \mathrm{C}$ for $2 \mathrm{~h}$ and proteins resolved with SDS/8\% PAGE;

B, Williams' (lane 1) and normal human (lane 2) plasmas were activated at $23^{\circ} \mathrm{C}$ for $20 \mathrm{~min}$ and proteins resolved with SDS/10\% PAGE;

C, Williams' (lane 1), normal human (lane 2) and orangutan (lane 3) plasmas were activated at $37^{\circ} \mathrm{C}$ for $15 \mathrm{~min}$ with protein resolution by SDS/7.5\% PAGE. Molecular masses of PK/kallikrein ( 85 and $88 \mathrm{kDa}$ ), $\sim 45-\mathrm{kDa}$ fragments, complexes of kallikrein with $\alpha_{2}$-macroglobulin (>400 kDa), C1 inhibitor (185 $\mathrm{kDa}$ ) and a $\sim 60-\mathrm{kDa}$ protein(s) (140 kDa) are indicated. 
not be evaluated because, in such a complex milieu like that of plasma, the degree of activation (not known in these plasmas) is expected to affect band numbers and positions.

A functional test based on the requirement of HK for optimum activation of plasma PK on a surface showed results similar to those obtained with Williams' and normal plasmas, except that a lower activation rate was apparent in the deficient plasma probably due to a lower amount of the protein in this plasma. Like normal plasmas, the HK/ LK-deficient plasma showed only the 85and $88-\mathrm{kDa}$ PK bands (Figure 1A). Also, the fact that the pattern of PK activation and distribution of the kallikrein formed among its inhibitors is similar in the Williams' and normal plasmas, although $\mathrm{HK}$ affects kallikrein binding to $\alpha_{2} \mathrm{M}$ but not to $\mathrm{C} 1$ inhibitor (25), further indicates the presence of a functional kininogen-like species. In addition, the similarity between the Williams' and normal plasma patterns at 4, 23 and $37^{\circ} \mathrm{C}$ (Figure 5), under conditions in which binding of kallikrein to $\alpha_{2} \mathrm{M}$ or $\mathrm{C} 1$ inhibitor depends on inhibitor concentrations and incubation temperatures (37-39), further indicates the presence of a kininogen-like function in the Williams' plasma. That kallikrein bound to $\alpha_{2} \mathrm{M}$ can hydrolyze D-Pro-PheArg-p-nitroanilide, while $\mathrm{C} 1$ inhibitor rapidly inhibits this kallikrein activity at $37^{\circ} \mathrm{C}$, may explain why, at $4^{\circ} \mathrm{C}$, Williams' plasma showed $8 \%$ of the amidolytic activity of that in normal plasma $(21,40)$ while at $37^{\circ} \mathrm{C}$ its amidolytic and clotting activities were undetectable. The negative results were probably due to rapid inactivation of the small amounts of kallikrein formed in the deficient plasma by $\mathrm{C} 1$ inhibitor, the main inhibitor of kallikrein at $37^{\circ} \mathrm{C}$. Concentrations of free kallikrein or kallikrein bound to $\alpha_{2} \mathrm{M}$ would be too low at $37^{\circ} \mathrm{C}$ to show clotting and amidolytic activities in Williams' plasma under conditions $\left(37^{\circ} \mathrm{C}\right)$ used for plasma assays.

To explain my finding of a $\sim 110-\mathrm{kDa}$ kininogen-like species in the plasma reported by Cheung et al. (19) to be totally deficient in $\mathrm{LK} / \mathrm{HK}$ due to the mutation in exon 5, I suggest an alternative consequence of this mutation: aberrant mRNA splicing with skipping of exon 5 yields the $110-\mathrm{kDa}$ kininogen-like species. In fact, exon 5 encodes 36 amino acids that, after glycosylation, might correspond to the $\sim 10-\mathrm{kDa}$ fragment missing in the deficient plasma. The bases for this suggestion are the following: 1) a mutation in an exon may result in skipping of that exon $(41) ; 2)$ in a patient, hereditary protein $\mathrm{S}$ deficiency has been found to be associated with skipping of an exon that harbored a $\mathrm{Ser}^{62} \rightarrow$ stop mutation in that exon (42); 3 ) Val-Val-Ala-Gly, a tetrapeptide in the reactive site of papain inhibitors (7), is encoded by both exons 5 and 8 , and 4) exon 5 encodes 36 of the 222 aa of domain 2, while exon 8 encodes 29 of the 116 aa of domain 3, homologous domains that exhibit similar functions as cysteine protease inhibitors $(7,8)$. Therefore, deletion of exon 5 should not greatly affect $\mathrm{HK}$ size or kinin and kininogen functions.

Questions were raised but not answered in this study due, at least in part, to the discontinuity of Williams' plasma supply the only plasma reported to have a total LK/ HK deficiency attributed by Cheung et al. (19) to premature protein termination. However, it is desirable and probably feasible, in future research, to identify the putative aberrant mRNA in stored, small amounts of platelet-rich Williams' plasma by using a transcription/polymerase chain reaction/cycle sequencing procedure, such as that described by Yamazaki et al. (43) and Okamoto et al. (42). For a better understanding of gene/ protein structures and $\mathrm{LK} / \mathrm{HK}$ function correlates, more studies are needed in newly discovered Williams' trait cases or in genes mimicking that of Williams' case. For example, mimic genes might be built by molecular means from normal LK/HK genes with the codon mutation ( $\operatorname{Arg}^{178} \rightarrow$ stop) in exon 
5 or with exon 5 deletion. Knock-out mice might also help to elucidate whether or not $\mathrm{LK} / \mathrm{HK}$ functions are crucial to a normal life.

\section{Acknowledgments}

I am grateful to Robert Guynn, M.D., Chairman of the Department of Psychiatry and Behavioral Sciences, University of Texas at Houston, for supporting this research and for his review of the manuscript. I am also grateful to Sesha Reddigari, Ph.D. and Allen
Kaplan, M.D. (Stony Brook Health Science Center), David Proud, Ph.D. (John Hopkins University) and A. Guillermo Scicli, Ph.D. (Henry Ford Hospital) for their gift of monoclonal and polyclonal antibodies, to Thomas Cosgriff, M.D. (Jefferson Oncology Clinic) for a critical reading of this manuscript, to Masao Tangi, Ph.D. for kindly preparing the photographs and sharing the procedure with me, and to the reviewers of this manuscript for their helpful critique and suggestions.

\section{References}

1. Cottrell GA \& Welsh ME (1966). Effects of synthetic eledoisin and bradykinin on certain invertebrate preparations and the isolated frog heart. Nature, 212: 838-839.

2. Rawlings ND \& Barrett AJ (1990). Evolution of proteins of the cystatin superfamily. J ournal of Molecular Evolution, 30: 6071

3. Fong D, Smith DI \& Hsieh W-T (1991). The human kininogen gene (KNG) mapped to chromosome 3q26-qter by analysis of somatic cell hybrids using the polymerase chain reaction. Human Genetics, 87: 189-192.

4. Takagaki $\mathrm{Y}$, Kitamura $\mathrm{N} \&$ Nakanishi $\mathrm{S}$ (1985). Cloning and sequence analysis of CDNAs for human high molecular weight and low molecular weight prekininogens. Primary structures of two human prekininogens. J ournal of Biological Chemistry, 260: 8601-8609.

5. Nakanishi S (1987). Substance P precursor and kininogen: their structures, gene organizations, and regulation. Physiological Reviews, 67: 1117-1142.

6. Müller-Esterl W, Fritz $\mathrm{H}$, Kellermann J, Lottspeich F, Machleidt W \& Turk V (1985). Genealogy of mammalian cystein proteinase inhibitors. Common evolutionary origin of selfins, cystatins and kininogens. FEBS Letters, 191: 221-226.

7. Ohkubo I, Kurachi K, Takasawa T, Shiokawa H \& Sasaki M (1984). Isolation of a human CDNA $\alpha 2$-thiol proteinase inhibitor and its identity with low molecular weight kininogen. Biochemistry, 23: 5691-5697.

8. Salvesen G, Parkes C, Abrahamson M, Grubb A \& Barrett AJ (1986). Human low$M_{r}$ kininogen contains three copies of a cystatin sequence that are divergent in structure and in inhibitory activity for cysteine proteinases. Biochemical J ournal, 234: 429-434.

9. Kraut H, Frey EK \& Bauer E (1928). Über ein neues Kreislaufhormon. HoppeSeyler's Zeitschrift für Physiologische Chemie, 175: 97-114.

10. Rocha e Silva M, Beraldo WT \& Rosenfeld G (1949). Bradykinin, a hypotensive and smooth muscle stimulating factor released from plasma globulin by snake venons and by trypsin. American J oumal of Physiology, 156: 261-273.

11. Werle E \& Berek U (1950). Über Kallidin. Biochemische Zeitschrift, 320: 136-145.

12. Armstrong $D$, J epson J $B$, Keele $C A \&$ Stewart J W (1957). Pain-producing substance in human inflammatory exudates and plasma. J ournal of Physiology, 135: 350-370.

13. Greene LJ, Stewart J M \& Ferreira SH (1970). Bradykinin-potentiating peptides from the venom of Bothrops jararaca. In: Sicuteri $F$, Rocha e Silva $M \&$ Back $N$ (Editors), Bradykinin and Related Kinins: Cardiovascular Biochemical and Neural Actions. Plenum Press, New York, London, 81-87.

14. Bhoola KD, Figueiroa $C D \&$ Worthy $K$ (1992). Bioregulation of kinins: kallikreins, kininogens and kininases. Pharmacological Reviews, 44: 1-80.

15. Majima M \& Katori M (1995). Approaches to the development of novel antihypertensive drugs: crucial role of the renal kallikrein-kinin system. Trends in Pharmacological Sciences, 16: 239-246.

16. Stewart J M (1995). Bradykinin antagonists: development and applications.
Biopolymers, 37: 143-155.

17. Schölkens BA (1996). Kinins in the cardiovascular system. Immunopharmacology, 33: 209-216.

18. Colman RW, Bagdasarian A, Talamo RC, Scott CF, Seavey M, Guimaraes J A, Pierce J V \& Kaplan AP (1975). Williams trait. Human kininogen deficiency with diminished levels of plasminogen proactivator and prekallikrein associated with abnormalities of the Hageman factor-dependent pathways. J ournal of Clinical Investigation, 56: 1650-1662.

19. Cheung PP, Kunapuli SP, Scott CF, Wachtfogel YT \& Colman RW (1993). Genetic basis of total kininogen deficiency in Williams' trait. J ournal of Biological Chemistry, 268: 23361-23365.

20. Reddigari S \& Kaplan AP (1988). Cleavage of human high-molecular weight kininogen by purified kallikrein and upon contact activation of plasma. Blood, 71: 13341340.

21. Reddigari SR \& Kaplan AP (1989). Monoclonal antibody to human high-molecularweight kininogen recognizes its prekallikrein binding site and inhibits its coagulation activity. Blood, 74: 695-702.

22. Scicli AG, Mindroiu T, Scicli $G \&$ Carretero OA (1982). Blood kinins, their concentration in normal subjects and in patients with congenital deficiency in plasma prekallikrein and kininogen. J ournal of Laboratory and Clinical Medicine, 100: 8193.

23. Proud D, Togias A, Naclerio RM, Crush SA, Norman PS \& Lichtenstein LM (1983). Kinins are generated in vivo following nasal airway challenge of individuals with allergen. J ournal of Clinical Investigation, 
72: 1678-1685.

24. van der Graaf F, Rietveld A, Keus FJ \& Bouma BN (1984). Interaction of human plasma kallikrein and its light chain with alpha 2-macroglobulin. Biochemistry, 23: 1760-1766.

25. Silverberg M, Longo J \& Kaplan AP (1986). Study of the effect of high molecular weight kininogen upon the fluid-phase inactivation of kallikrein by $\mathrm{Cl}$ inhibitor. J ournal of Biological Chemistry, 261: 14965-14968.

26. Veloso D (1996). Reexamining the enigma of the kininogens: they are multifunctional proteins but humans lacking them are clinically asymptomatic. FASEB J oumal, 10: 1526 (Abstract).

27. Veloso D, Smith J I, Denny S \& Cosgriff TM (1992). Structure, kinetics and function of human and rhesus plasma prekallikreins are similar. Thrombosis and Haemostasis, 68: 526-533.

28. Veloso $D$, Silver LD, Hahn $S \&$ Colman RW (1987). A monoclonal anti-human plasma prekallikrein antibody that inhibits activation of prekallikrein by factor XIIa on a surface. Blood, 70: 1053-1062.

29. Proctor PR \& Rapaport SI (1961). The partial thromboplastin time with kaolin: A simple screening test for first stage plasma clotting deficiencies. American J ournal of Clinical Pathology, 36: 212-219.

30. Fraker PM \& Speck J r J C (1978). Protein and cell membrane iodinations with a sparingly soluble chloramide, $1,3,4$, 6tetrachloro, $3 \alpha, 6 \alpha$-diphenylglycoluril. Biochemical and Biophysical Research Communications, 80: 849-857.
31. Laemmli UK (1970). Cleavage of structural proteins during the assembly of the head of bacteriophage T4. Nature, 227: 680-685.

32. Towbin H, Staehelin T \& Gordon J (1979). Electrophoretic transfer of proteins from polyacrylamide gels to nitrocellulose sheets: Procedure and some applications. Proceedings of the National Academy of Sciences, USA, 76: 4350-4354.

33. Burnette WN “Western Blotting” (1981). Electrophoretic transfer from sodium dodecyl sulfate-polyacrylamide gels to unmodified nitrocellulose and radiographic detection with antibody and radioiodinated protein. Analytical Biochemistry, 112: 195-203.

34. Veloso D \& Colman RW (1991). Western blot analyses of prekallikrein and its activation products in human plasma. Thrombosis and Haemostasis, 65: 382-388.

35. Tayeh MA, Olson ST \& Shore J D (1994). Surface-induced alterations in the kinetic pathway for cleavage of human high molecular weight kininogen by plasma kallikrein. J ournal of Biological Chemistry, 269: 16318-16325.

36. Veloso D (1988). Contact activation system and its interaction with other plasma pathways. Arquivos de Medicina, 2: 2228.

37. Veloso D, Tseng SY, Craig AR \& Colman RW (1989). Binding of a monoclonal antihuman plasma prekallikrein antibody to the complexes of kallikrein with $\mathrm{Cl}$ inhibitor and $\alpha_{2}$-macroglobulin analyzed by immunoblot and "sandwich" assays. Advances in Experimental Medicine and $\mathrm{Bi}$ - ology, 247 (Part A): 499-505.

38. Harpel PC, Lewin MF \& Kaplan AP (1985). Distribution of plasma prekallikrein between $\mathrm{C} 1$ inactivator and $\alpha_{2}$-macroglobulin complexes. J ournal of Biological Chemistry, 260: 4257-4263.

39. Veloso D \& Campbell G (1992). Computerized immunoblot analyses (CIBA) of the distribution of prekallikrein and its activation products in vivo and in vitro. Agents and Actions, 38 (Suppl): 166-173.

40. van der Graaf F, Keus FJ A, Vlooswijk RAA $\&$ Bouma BN (1982). The contact activation mechanism in human plasma: activation induced by dextran sulfate. Blood, 59: 1225-1233.

41. Steingrimsdottir H, Rowley G, Dorado G Cole J \& Lehmann AR (1992). Mutations which alter splicing in the human hypoxanthine-guanine phosphoribosyltransferase gene. Nucleic Acids Research, 20: 1201-1208.

42. Okamoto $Y$, Yamazaki $\mathrm{T}$, Katsumi $\mathrm{A}$ Kojima T, Takamatsu J , Nishida M \& Saito H (1996). A novel nonsense mutation associated with an exon skipping in a patient with hereditary protein $\mathrm{S}$ deficiency type I. Thrombosis and Haemostasis, 75: 877-882.

43. Yamazaki $T$, Hamaguchi $M$, Katsumi $A$, Kagami K, Kojima T, Takamatsu J \& Saito H (1995). A quantitative protein $S$ deficiency associated with a novel nonsense mutation and markedly reduced levels of mutated mRNA. Thrombosis and Haemostasis, 74: 590-595. 